\title{
Basal ganglia circuits underlying the pathophysiology of levodopa-induced dyskinesia
}

\author{
Pedro Barroso-Chinea and Erwan Bezard* \\ Centre National de la Recherche Scientifique UMR 5227, Bordeaux Institute of Neuroscience, Université Victor-Segalen Bordeaux 2, Bordeaux, France
}

\section{Edited by:}

Jose L. Lanciego,

University of Navarra, Spain

\section{Reviewed by:}

Jose L. Lanciego,

University of Navarra, Spain

Marco Aurelio M. Freire, Federal

University of Rio Grande do Norte,

Brazil

\section{*Correspondence}

Erwan Bezard, CNRS UMR 5227, 146

rue Léo Saignat, 33076 Bordeaux

Cedex, France.

e-mail: erwan.bezard@u-bordeaux2.fr
Involuntary movements or dyskinesia, represent a debilitating complication of levodopa therapy for Parkinson's disease. Dyskinesia is, ultimately, experienced by the vast majority of the patients. Despite the importance of this problem, little was known about the cause of dyskinesia, a situation that has dramatically evolved in the last few years with a focus upon the molecular and signaling changes induced by chronic levodopa treatment. Departing from this, we here review the progress made in functional anatomy and neuroimaging that have had a tremendous impact on our understanding of the anatomo-functional organization of the basal ganglia in Parkinsonism and dyskinetic states, notably the demonstration that dyskinesia are linked to a pathological processing of limbic and cognitive information.

Keywords: Parkinson's disease, levodopa, basal ganglia, abnormal involuntary movements
Parkinson'sdisease(PD) is thesecondmostcommonneurodegenerative disorder after Alzheimer's disease, which neuropathological hallmark is the degeneration of dopaminergic neurons in the substantia nigra pars compacta $(\mathrm{SNc})$. The loss of dopaminergic input to the striatum results in the depletion of dopamine that causes a cascade of functional modifications that involves all components of the basal ganglia circuitry. These changes are thought to represent the neural substrate for parkinsonian motor symptoms such as bradykinesia (slowness of movement), rigidity (stiffness), and tremor. However, other neurotransmitter systems (e.g., cholinergic, adrenergic, serotoninergic) also degenerate and cell loss is seen in other brain stem nuclei and the cortex (Braak et al., 2002; Chaudhuri et al., 2006). This non-dopaminergic degeneration is thought to be the major cause of the non-motor symptoms of PD (e.g., cognitive decline, autonomic dysfunction). Dopaminergic drugs (e.g., dopamine precursor drug, L-3,4-dihydroxyphenylalanine - levodopa), dopamine agonists and the inhibitors of dopamine catabolism are the main therapeutic options for alleviating the parkinsonian motor symptoms.

\section{INCIDENCE AND PHENOMENOLOGY OF DYSKINESIA}

However, as PD patients receive chronic treatment with levodopa upon a progressive disease, they gradually develop two clinical phenomena requiring changes in their clinical management: fluctuations in motor response and a variety of abnormal involuntary

Abbreviations: CM, centromedian nucleus; 2-DG, 2-deoxyglucose; D1 dopamine receptor; D2R, D2 dopamine receptor; FDG, fluorodeoxyglucose; GABA, gamino-butyric acid; GAD, glutamic acid decarboxylase; GPe, globus pallidus pars externa; GPi, globus pallidus pars interna; IT, intratelencephalic corticostriatal neurons; LID, levodopa-induced dyskinesia; MPTP, 1-methyl-4-phenyl-1,2,3,6tetrahydropyridine; MSN, medium spiny neurons; 6-OHDA, 6-hydroxydopamine, PD, Parkinson's disease; PDRP, Parkinson's disease-related pattern; PET, positron emission tomography; Pf, parafascicular nucleus; PPE-A, preproenkephalin A; PPE-B, preproenkephalin-B; PPT, pedunculopontine tegmental nucleus; PT, pyramidal tract; $\mathrm{SNc}$, substantia nigra pars compacta; $\mathrm{SNr}$, substantia nigra pars reticulata; SPECT, single photon emission computed tomography; STN, subthalamic nucleus. movements, known as levodopa-induced dyskinesia (LID) (Yahr et al., 1968). The frequency of these motor complications has been estimated between 40 and 50\%, after 4-6 years of levodopa treatment (Ahlskog and Muenter, 2001) but increases to $90 \%$ after 10 years of treatment (Rascol et al., 2000). Despite its frequency and clinical significance, the pathophysiology and the clinical risk factors causing dyskinesia in PD are not understood. The incidence is estimated at about $10 \%$ per year after initiating levodopa therapy. Some people exhibit severe dyskinesia very rapidly, whereas others do not develop this complication despite many years of levodopa treatment. The phenomenology of dyskinesia encompasses various forms: chorea, athetosis, dystonia, stereotypy, ballismus, or a combination of these. In addition to levodopa-induced motor fluctuations, PD patients can frequently experience affective, motivational, and cognitive disorders (Ahlskog and Muenter, 2001). The development of dyskinesia has been reported to depend on several clinical risk factors, such as duration of disease, severity of disease, duration of levodopa treatment and actual, or cumulative levodopa dose. Numerous important advances have been made in understanding of the etiopathogenesis, pathology and clinical phenomenology of PD and LID over the past 10 years.

\section{BASAL GANGLIA ANATOMICAL ORGANIZATION}

The basal ganglia comprise a group of interconnected subcortical nuclei located at the base of the cerebral hemispheres, with parts belong to the forebrain, diencephalon, and midbrain. The basal ganglia nuclei include the striatum (caudate and putamen), the globus pallidus pars externa (GPe) and pars interna (GPi), the subthalamic nucleus (STN) and the substantia nigra, divided into its pars compacta $(\mathrm{SNc})$ and pars reticulata $(\mathrm{SNr})$. Current knowledge suggests that the basal ganglia constitute a highly organized network, whose functional organization is complex. There is a clear consensus in considering that input to the basal ganglia from different cortical areas terminates within specific basal ganglia territories, which are connected to similarly specific portions of the thalamus. 
These thalamic areas, in turn, project back to the same areas of the cortex from which the circuit originates (Alexander et al., 1986; Kelly and Strick, 2004; DeLong and Wichmann, 2007). Numerous data suggest that the basal ganglia nuclei are involved in movement control, as well as associative learning, planning, working memory, and emotion (Hikosaka et al., 2002; Pasupathy and Miller, 2005; Yin and Knowlton, 2006).

At present, there is a classical model of movement disorders in basal ganglia disease, developed in the late 1980s (Alexander et al., 1986; Crossman, 1987; Albin et al., 1989), both describing the neural mechanisms underlying parkinsonian akinesia and explaining the appearance of abnormal involuntary movements (dyskinesia). These represent two diametrically opposed mechanisms. However, the limitations and pitfalls of these models have also been discussed extensively on several occasions (Wichmann and DeLong, 1996; Obeso et al., 1997; Rodriguez-Oroz et al., 2009). The classical box and arrows basal ganglia model (Crossman, 1987; Albin et al., 1989; DeLong, 1990) proposes a motor circuit consisting of two input structures, comprising the striatum and STN, two output structures ( $\mathrm{GPi}$ and $\mathrm{SNr}$ ) and two intrinsic structures, including GPe and SNc (Mink, 1996). The striatum and the STN receive topographically organized input from the cerebral cortex (Monakow et al., 1979; Nambu et al., 1997; Lei et al., 2004) whereas the GPi and the SNr provide basal ganglia output to the thalamus and brainstem (Carpenter et al., 1976; Parent and De Bellefeuille, 1982; Francois et al., 1984; Oertel and Mugnaini, 1984).

The striatum receives massive cortical excitatory inputs (Kemp and Powell, 1970; Kitai et al., 1976; McGeer et al., 1977; Cherubini et al., 1988) and is densely innervated by dopamine from the SNc (Faull and Mehler, 1978; Beckstead et al., 1979). In the striatum, the major neuronal population is represented by medium spiny neurons (MSNs), accounting for almost $95 \%$ of total striatal cells (Kemp and Powell, 1971). MSNs use g-amino-butyric acid (GABA) as a inhibitory neurotransmitter (Kita and Kitai, 1988). They form two main populations of projection neurons (striatofugal system) that differ in their expression of the receptors that mediate the effect of dopamine. The striatonigral MSNs that monosynaptic project to GPi and the $\mathrm{SNr}$ (direct pathway) express preferentially dopamine D1 receptors (D1R) and produce the neuropeptides dynorphin and substance $\mathrm{P}$ whereas the striatopallidal MSNs that project to $\mathrm{GPe}$ (indirect pathway) express dopamine $\mathrm{D} 2$ receptors (D2R) and enkephalin (Gerfen et al., 1990). Although this strict "segregation" was supported by previous studies, a significant number of D1R and D2R-coexpressing neurons (about 5-10\%) were found in rat (Le Moine and Bloch, 1995) and primate (Aubert et al., 2000) using double in situ hybridization technique. In this same line, anatomical studies clearly show that single striatofugal axons arborize in both pallidal segments in rodents (Kawaguchi et al., 1990; Castle et al., 2005) and in primates (Parent and Hazrati, 1995; Levesque and Parent, 2005; Nadjar et al., 2006). These data indicate that the striatofugal system is not as functionally segregated in rodents and primates as previously considered in the current model of basal ganglia. Dopamine modulates glutamatergic effects on corticostriatal inputs by exerting a dual effect on striatal neurons, exciting D1R neurons in the direct pathway and inhibiting D2R neurons in the indirect circuit. Within this general context, activation of direct-pathway circuits has been proposed to facilitate or select appropriate movements, whereas activity in the indirect pathway may inhibit unwanted or inappropriate movements (Albin et al., 1989; Alexander et al., 1990). Clearcut demonstration of such roles has just been released using optogenetic approaches (Kravitz et al., 2010).

The GPe and the STN are classically viewed as part of the socalled indirect pathway (Parent and Hazrati, 1995). The GPe, principally sends GABAergic projections to the STN (Albin et al., 1989; Alexander et al., 1990; DeLong, 1990) but anatomical studies have revealed the existence of new efferent projections of the GPe to the two output structures of the basal ganglia (Hazrati et al., 1990; Kincaid et al., 1991). The STN is an important control structure of basal ganglia circuits, being the only glutamatergic nucleus of the network (DeLong and Wichmann, 2007). The STN, like the other components of the basal circuit, is subdivided into different territories, motor, oculomotor, associative, and limbic, each with different connections and functions (Parent and Hazrati, 1995; Bevan et al., 2006). The large dorsolateral portion of the STN corresponds to the motor territory; the ventromedial portion to the associative territory and the medial tip to the limbic territory of the STN.

Most STN neurons are glutamatergic projection neurons and provide a powerful excitatory input to the GPe (Van Der Kooy and Hattori, 1980; Kita and Kitai, 1987; Parent et al., 2000; Castle et al., 2005) and to the two output structures of the basal ganglia (Parent and Smith, 1987; Smith et al., 1990). Additionally a subpopulation of efferent STN neurons innervate directly the ventral motor thalamic nuclei (Nauta and Cole, 1978; Rico et al., 2010). The STN also has important reciprocal connections with the pedunculopontine tegmental nucleus (PPT) (Hammond et al., 1983; Jackson and Crossman, 1983; Kita and Kitai, 1987; Granata and Kitai, 1989; Steininger et al., 1992) as well as the cerebral cortex (Jackson and Crossman, 1981; Nambu et al., 2002; Degos et al., 2008). Furthermore, as inputs to both striatum and STN arise from the intralaminar thalamic nuclei, the centromedian nucleus (CM), and the parafascicular nucleus (Pf) (Wilson et al., 1983; Sadikot et al., 1992; Feger et al., 1994; Lanciego et al., 2004; Castle et al., 2005), the STN is now viewed as a key entry to the basal ganglia circuit, probably as important as the striatum itself.

The GPi and SNr share many histological characteristics, as well as similar afferent and efferent connections. Although the projection neurons of the basal ganglia output nuclei are generally considered to be GABAergic (Penney and Young, 1981; Rajakumar et al., 1994), there is evidence that projection neurons within the entopeduncular nucleus (ENT, the rodent homolog of GPi) also express other markers such as markers of cholinergic (Parent et al., 1981) and glutamatergic neurons (Kha et al., 2000), as well as peptides like somatostatin and substance P (Murakami et al., 1989a,b). Both nuclei project to the ventral motor thalamus, caudal intralaminar nuclei (Sidibe et al., 1997, 2002) and PPT (Steininger et al., 1992; Grofova and Zhou, 1998). Finally the thalamic nuclei then send glutamatergic projections to the motor cortex, thus closing the loop.

\section{THE STRIATUM, FOCUS OF MOST STUDIES}

Dyskinesia in PD seems to be mediated by alterations in basal ganglia activity that are the opposite of those occurring in PD (Vidailhet et al., 1999; Obeso et al., 2000; Boraud et al., 2001). Current 
models of LID suggest that excessive decrease in GPi activity in turn disinhibits the motor thalamus and the cortex, giving rise to abnormal increase in cortical drive and consequent excessive motor movements (Wichmann and DeLong, 1996; Bezard et al., 2001a).

The first site of interest is of course the striatum with a particular emphasis upon the MSNs. Over the past few years, LID have been associated with a number of molecular changes, including regulation of striatal dopamine receptors, downstream changes in striatal proteins and genes, abnormalities in non-dopaminergic transmitter systems, etc., all changes that go beyond the topic of the present review (Bezard et al., 2001a; Jenner, 2008). Changes are not simply the consequence of chronic treatment since the first levodopa dose would induce expression changes of numerous proteins in the dopamine depleted striatum that equate those induced by chronic exposure as evidenced using a proteomic approach in the MPTP macaque model (Scholz et al., 2008).

\section{DENDRITIC SPINE PRUNING OCCURS ON D2-EXPRESSING MSNs}

A simple but long ignored question was the possible changes in the connections in the basal ganglia circuit in both the parkinsonian and dyskinetic states. Recently, Nadjar et al. (2006) showed that both the phenotype and the targets of striatofugal neurons, and therefore their relative influence on target structures, is preserved after dopamine denervation in the parkinsonian state and after additional chronic levodopa treatment in both non-dyskinetic and dyskinetic groups (Nadjar et al., 2006). This suggests that the phenotypic plasticity of the striatofugal system is not affected by the experimental condition. It does not mean however that plastic changes do not occur in the striatum. For instance, it has been shown that the size of the dendritic tree and the density of dendritic spines of MSNs is significantly reduced in the caudate nucleus and the putamen of PD patients compared with controls (Stephens et al., 2005), confirming previous data in rodents (Ingham et al., 1998). Such pruning was observed in MPTP-primates as well (Scholz et al., 2008; Villalba et al., 2009). The MSNs submitted to this dramatic plastic change were recently characterized as the D1R-immunonegative neurons, i.e., the D2R-expressing neurons (Day et al., 2006). Unfortunately, the impact of such spine pruning on MSN physiology is still unclear. These data nevertheless support the idea of plastic changes in the corticostriatal network but with no consequence on the phenotype and organization of projections of striatal neurons. Thus, loss of cortical afferents appears unlikely to affect the phenotypic pattern of striatal neurons, but rather might alter their activity or mRNA processing (Day et al., 2006). Altogether, these changes contribute in the development of adverse events related to levodopa therapy, because they would alter information flow through the striatum and rest of the basal ganglia nuclei.

\section{IS THE DIRECT/INDIRECT PATHWAY IMBALANCE CAUSED BY DIFFERENTIAL CORTICOSTRIATAL INPUT?}

Many studies have investigated the pathophysiology of the basal ganglia after dopamine denervation. Imbalances between neural activity in the two major output pathways of striatum have been proposed to underlie the profound motor deficits observed in PD, such as the hypokinesia (Albin et al., 1989; DeLong, 1990; Bezard et al., 2001b). This imbalance was first documented in anatomo-functional studies (Gerfen et al., 1990; Gerfen, 2000) and, surprisingly, only very recently confirmed with an electrophysiological approach (Mallet et al., 2006). Such an imbalance could be generated locally within the striatum or caused by a complex interaction with the corticostriatal excitatory. Retrograde tract-tracing experiments in the rat have shown that striatonigral neurons are preferentially innervated by cortical neurons that project inside the telencephalon (intratelencephalic (IT)-type), in both the ipsilateral and contralateral striatum, whereas striatopallidal neurons receive a greater input from cortical neurons that send their main axon into the pyramidal tract (PT) and their collateral axons only in the ipsilateral striatum (Lei et al., 2004). Although such a clearly segregated corticostriatal organization has recently been challenged (Ballion et al., 2008), a deficit in specific cortical inputs might also contribute to selectively depress the activity of striatonigral neurons (Mallet et al., 2006). Both the spontaneous activity and the sensitivity to cortical stimulation of striatonigral neurons were reduced by the lesion, whereas the reverse effects were observed for striatopallidal neurons (Mallet et al., 2006). However, elegant electrophysiological studies have shown that the decreased IT neuron activity associated with the dopaminergic depletion does not contribute to the striatal imbalance (Ballion et al., 2008).

\section{STRIATAL GLUTAMIC ACID DECARBOXYLASE mRNA LEVELS IN PD AND LID}

While electrophysiological investigations are scarce, anatomofunctional studies have documented the specific changes in the transcriptional activity of subpopulations of striatal GABA neurons in PD and LID conditions. Outside the scope of this review, a number of studies have indirectly confirmed the anatomo-functional organization of the striatal territories. Immediate-early genes have been extensively studied and expression patterns of c-fos and FosB proteins clearly relate a given behavioral phenotype with an increased expression/signal in a sub-territory of the striatum (Saka et al., 1999; Cenci, 2002; Jenner, 2008).

For instance, a number of studies using in situ hybridization studies have unraveled changes in glutamic acid decarboxylase (GAD) mRNA levels, the rate-limiting enzyme in the synthesis of GABA, in parkinsonian and dyskinetic animal models. Studies carried out during the last 25 years have shown the existence of two $\mathrm{GAD}$ isoforms, $\mathrm{GAD}_{65}$, and $\mathrm{GAD}_{67}$, each encoded by a different gene, and differing in molecular size and intraneuronal distribution (Denner and Wu, 1985; Kaufman et al., 1991; Martin et al., 1991; Martin and Rimvall, 1993). In MPTP-treated primates, $\mathrm{GAD}_{65}$ mRNA and $\mathrm{GAD}_{67}$ mRNA are increased in the striatum (Pedneault and Soghomonian, 1994; Soghomonian et al., 1994; Levy et al., 1995). Levodopa treatment significantly normalizes $\mathrm{GAD}_{67}$ mRNA expression in the putamen and caudate nucleus to levels similar to those found in control monkeys (Levy et al., 1995). Other studies, however, showed not significant changes in the distribution of both isoforms in the cortex, caudate, and putamen of parkinsonian and dyskinetic primates (Stephenson et al., 2005). In rats bearing a unilateral 6-OHDA lesion, GAD gene expression is increased in the striatum on the side of the lesion (Lindefors et al., 1989; Soghomonian et al., 1992; Consolo et al., 1999; Bacci et al., 2002). By contrast, the administration of levodopa leads to further increases in striatal GAD 67 mRNA levels (Cenci et al., 1998; Consolo et al., 1999; Carta et al., 2001, 2003; Bacci et al., 2002; Nielsen and Soghomonian, 2004). 


\section{OPIOID PEPTIDE PRECURSOR mRNA AND OPIOID RECEPTOR LEVELS IN PD AND LID}

Besides GAD, expression levels of precursors of the opioid peptides have been extensively investigated. Investigations in rodents (Gerfen et al., 1990; Engber et al., 1992; Duty et al., 1998), primates (Herrero et al., 1995; Morissette et al., 1999; Tel et al., 2002) and humans (Nisbet et al., 1995; Calon et al., 2002; Henry et al., 2003) have shown that Parkinsonism is associated with an increased expression of the opioid precursor preproenkephalin-A (PPE-A) messenger RNA (mRNA) in striatal neurons projecting to the GPe and a decreased preproenkephalin-B (PPE-B) mRNA expression in striatal neurons projecting to the GPi. In the dyskinetic state, however, the expression of PPE-B mRNA is increased (Cenci et al., 1998; Duty et al., 1998; Henry et al., 1999; Westin et al., 2001; Tel et al., 2002; Winkler et al., 2002; Henry et al., 2003), whereas that of PPE-A mRNA is either unchanged or further increased (Herrero et al., 1995; Morissette et al., 1997; Duty et al., 1998; Henry et al., 1999; Morissette et al., 1999; Zeng et al., 2000; Westin et al., 2001; Calon et al., 2002; Tel et al., 2002). These data suggest a role for enhanced endogenous opioid peptide transmission in striatal output pathways for the generation of LID. However, none of these studies has regarded basal ganglia nuclei other than the striatum as potential sources and those opioid precursors have almost never been quantified, simultaneously with the levels of opioid receptors, at the peak of dyskinesia severity, a quite surprising observation. Recently, Aubert and colleagues, studying a comprehensive brain bank of control, parkinsonian and dyskinetic monkeys terminated at the peak of levodopa-induced antiparkinsonian efficacy and dyskinesia manifestation, found a reduction in $\kappa$ and $\mu$ opioid receptor binding in the GPi correlating with dyskinesia severity. Such decrease also correlated with an enhanced expression of PPE-B mRNA, but not that of PPE-A, in both the striatum and the STN, known to also express peptide precursors (Merchenthaler et al., 1997). This abnormal PPE-B-derived transmission could therefore be involved in LID manifestation with increased peptide levels arising from both the striatum and the STN (Aubert et al., 2007).

\section{TRANSCRIPTOMIC CHANGES AFFECTING PALLIDAL COMPLEX AND STN IN PD AND LID}

In the 6-OHDA-lesioned rat model of PD, the profound dopamine depletion in the striatum resulted in significant increases in the percentage of GPe neurons that expressed GADs mRNA and in the amount of GADs mRNA per GPe neuron (Kincaid et al., 1992; Soghomonian and Chesselet, 1992). Similar results were described MPTP-treated monkeys, the expression of $\mathrm{GAD}_{67}$ but not $\mathrm{GAD}_{65}$ was augmented in the GPe, along with a significant increases in number of $\mathrm{GAD}_{67}$ neurons, while no significant difference in the number of $\mathrm{GAD}_{65}$ neurons was observed (Stephenson et al., 2005). Levodopa treatment did not significantly change the number of $\mathrm{GAD}_{65}$ or $\mathrm{GAD}_{67}$-expressing pallidal neurons following MPTP (Stephenson et al., 2005).

In the GPi of MPTP-treated monkeys, i.e., the main output structure, the expression of $\mathrm{GAD}_{67}$ and $\mathrm{GAD}_{65} \mathrm{mRNAs}$ is increased (Pedneault and Soghomonian, 1994; Soghomonian et al., 1994; Herrero et al., 1996). Similar results were described in MPTPlesioned cats (Schroeder and Schneider, 2001). Interestingly the increase in $\mathrm{GAD}_{67}$ mRNA is abolished by levodopa treatment in
MPTP-treated monkeys (Herrero et al., 1996). These data fit with the observation that there is no difference in the levels of $\mathrm{GAD}_{67}$ mRNA between levodopa-treated PD patients and control subjects (Herrero et al., 1996), i.e. that levodopa treatment normalizes $\mathrm{GAD}_{67}$ mRNA levels. In rats, an ipsilateral marked up-regulation of $\mathrm{GAD}_{65} /{ }_{67}$ mRNA expression in the ENT nucleus has been reported following 6-OHDA lesion (Soghomonian and Chesselet, 1992; Barroso-Chinea et al., 2008). Continuous or intermittent levodopa administration is equally effective at reversing the lesion-induced increase in $\mathrm{GAD}_{67}$ mRNA expression in the ENT nucleus (Nielsen and Soghomonian, 2004). Altogether, these results indicate that the level of $\mathrm{GAD}_{67}$ mRNA is increased in the cells of the GPi after nigrostriatal dopaminergic denervation and that this increase can be reversed by levodopa therapy (Herrero et al., 1996).

One should however keep in mind that a transcriptional regulation does not necessarily mean a change in electrical activity. Parallel to these observations, there are evidences of an increase in mitochondrial respiratory chain enzyme activity in ENT nucleus in the lesioned hemisphere of 6-OHDA rats suggesting increased synaptic activity, perhaps due to increased firing of the STN (Porter et al., 1994). The enzymatic activity or the changes in the expression of cytochrome oxidase-I (COI) have indeed been shown to correlate with changes in the firing activity of several structures (Wong-Riley and Welt, 1980; Wong-Riley, 1989). "In situ" hybridization of cytochrome oxidase-I (COI) mRNA in the MPTP monkey model of PD has shown increased levels parallel increased firing of the STN (Bergman et al., 1994; Vila et al., 1996; Bezard et al., 1999). Comparably, increased levels in the GPi correlate with an increased firing frequency of GPi neurons (Bezard et al., 1999; Boraud et al., 2000, 2001). As expected, levodopa treatment reversed such COI mRNA overexpression in all affected structures (Vila et al., 1996). Similar results were obtained in the 6-OHDA rat model (Vila et al., 1999). No changes were however detected in levodopa-treated PD patients compared to control subjects, a situation that could either reflect the levodopa-induced normalization of the COI mRNA expression in PD patients or the inescapable poor quality of human post-mortem samples (Vila et al., 1996). In conclusion, these anatomo-functional evidences correlate with the observed hypoactivity of both the STN and GPi during levodopa or apomorphine-induced dyskinesia in MPTP-treated monkeys (Filion et al., 1991; Boraud et al., 2001), in dyskinetic PD patients (Merello et al., 1999) and in patients with generalized dystonia and hemiballismus (Suarez et al., 1997; Vitek et al., 1999).

\section{“PARKINSON'S DISEASE-RELATED PATTERN" IN PD AND LID}

Considerable efforts have been devoted to develop neuroimaging methods to study the basal ganglia (Eidelberg and Edwards, 2000; Feigin et al., 2001; Eckert et al., 2005; Asanuma et al., 2006; Trost et al., 2006; Eidelberg, 2009). These techniques have been developed with the hope that they could be used as biomarkers to help the diagnosis, to detect early stages of the disease, later on to grade the disease severity of the disease, and, finally, to serve as a surrogate marker for progression of the underlying disease. Positron emission tomography (PET) and single photon emission computed tomography (SPECT), which is less sensitive but more widely available than PET, are capable to provide an objective measure of PD severity as both techniques depict the loss of neurotransmitter 
function and can detect changes in striatal dopamine levels after levodopa administration in relationship with the motor responses. Such investigations of the dopamine transmission have brought extremely important insights, even unraveling the physiological basis for the placebo effect (de la Fuente-Fernandez et al., 2001), but they do not impact our understanding of the functional anatomy of PD and LID. Metabolic PET studies, however, have demonstrated that PD is characterized by a set of reproducible functional brain networks that correlate with its clinical features (Huang et al., 2007). Using $\left[{ }^{18} \mathrm{~F}\right]$ fluorodeoxyglucose (FDG) and PET, changes in a so-called Parkinson's disease-related pattern (PDRP) expression have been observed. Disease progression is associated with increasing metabolism in the STN and GPi, as well as in the dorsal pons and primary motor cortex. Advancing disease is associated with declining metabolism in the prefrontal and inferior parietal regions (Huang et al., 2007). Changes in a cognition-related network paralleled these motor-related changes. At present, there is a clear consensus in considering that the PDRP is characterized by increased pallido-thalamic and pontine activity, associated with relative reductions in cortical motor and premotor areas in $\mathrm{PD}$ patients (Carbon et al., 2003; Eidelberg, 2009) although no changes are reported in the thalamus. The impact of dopaminergic therapy upon PDRP has also been investigated (Feigin et al., 2001; Asanuma et al., 2006). The changes in the pallidal metabolism and the overall PDRP network activity correlated significantly with clinical improvement of PD symptoms during dopaminergic treatment (Feigin et al., 2001; Asanuma et al., 2006). Interestingly, a recent study (Hirano et al., 2008) showed a highly significant dissociation between levodopa-mediated PDRP changes in cerebral blood flow and glucose metabolic scans. This phenomenon was accentuated in PD patients with LID, reflecting excessive dopaminergic-induced vasodilatation in these subjects.

What is clear from these studies is that not only the PDRP is affected by dopaminergic treatments but the cognition-related pattern as well. Such findings have lead to dig in the experimental literature when researchers used the then-popular 2-deoxyglucose (2-DG) accumulation technique for studying brain metabolism. Alan Crossman and his colleagues extensively studied the metabolic changes induced by dopamine depletion and further dopaminergic treatments. Of particular interest for this review, they found that the STN showed a dramatic increase in 2-DG uptake in animals exposed to dopamine agonist immediately prior to the terminal procedure, especially in ventromedial "limbic/associative" STN, along with relative greater levels of 2-DG uptake in GPi (Mitchell et al., 1989, 1992). This suggested that a major effect of dopaminergic treatment was to affect the limbic/associative network more than

\section{REFERENCES}

Ahlskog, J. E., and Muenter, M. D. (2001). Frequency of levodopa-related dyskinesias and motor fluctuations as estimated from the cumulative literature. Mov. Disord. 16, 448-458.

Albin, R. L., Young, A. B., and Penney, J. B. (1989). The functional anatomy of basal ganglia disorders. Trends Neurosci. 12, 366-375.

Alexander, G. E., Crutcher, M. D., and DeLong, M. R. (1990). Basal

the motor network. Since consistent funneling of information takes place between the sensorimotor, limbic, and associative cortico-basal ganglia domains (Haber et al., 1993, 2000), we hypothesized that non-motor domains play a role in these manifestations and studied the changes in 2-DG accumulation in the sensorimotor, limbic, and associative domains of basal ganglia and thalamic nuclei of four groups of non-human primates (Guigoni et al., 2005): normal, parkinsonian, parkinsonian chronically treated with L-dopa without exhibiting dyskinesia and parkinsonian chronically treated with levodopa and exhibiting overt dyskinesia. While non-dyskinetic animals displayed a rather normalized metabolic activity, dyskinetic animals were distinguished by significant changes in 2-DG accumulation in limbic and associative-related structures and not simply in sensorimotor-related ones, suggesting that dyskinesia are linked to a pathological processing of limbic and cognitive information (Guigoni et al., 2005). These metabolic changes likely reflect the underlying neural mechanisms of not simply motor dyskinesia but also affective, motivational, and cognitive disorders associated with long-term exposure to levodopa.

\section{CONCLUDING REMARKS}

The anatomical and functional organization of the basal ganglia circuitry has received considerable attention in the last two decades. This has led to a better understanding of the physiological and pathophysiological aspects involved in PD and LID. To our opinion, the most fundamental consequence of the recent findings is that we cannot continue analyzing LID by investigating the only motor areas, thus rendering unreliable all studies that do not pay attention to the anatomo-functional organization of cortico-basal ganglia loops. Seeing LID as either "caused" by unwanted involvement of associative and limbic areas or simply as having their cognitive and limbic abnormal counterparts ("consequence") as often reported in hyperkinetic disorders might have different clinical consequences. For instance, if electrophysiological investigations support the causative hypothesis, modulating the activity of nonmotor regions would reduce LID severity, thereby offering new drug targets for treatment of this debilitating condition.

\section{ACKNOWLEDGMENTS}

The Université Victor-Segalen Bordeaux 2 and the Centre National de la Recherche Scientifique provided the infrastructural support. This review was supported by an Agence Nationale de la Recherche grant (Erwan Bezard), a, Spanish Ministry of Education (PBC - Programa José Castillejo; referencia: JC2009-00282), a Marie Curie Intraeuropean Fellowship (PBC - grant no. 252598; FP7-PEOPLE-2009-IEF) and by the UTE-project/FIMA (PBC).

Network modulation in the treatment of Parkinson's disease. Brain 129, 2667-2678.

Aubert, I., Ghorayeb, I., Normand, E., and Bloch, B. (2000). Phenotypical characterization of the neurons expressing the D1 and D2 dopamine receptors in the monkey striatum. J. Comp. Neurol. 418, 22-32.

Aubert, I., Guigoni, C., Li, Q., Dovero, S., Bioulac, B.H., Gross, C. E., Crossman, A. R., Bloch, B., and Bezard, E.
(2007). Enhanced preproenkephalinB-derived opioid transmission in striatum and subthalamic nucleus converges upon globus pallidus internalis in L-3,4-dihydroxyphenylalanineinduced dyskinesia. Biol. Psychiatry 61, 836-844.

Bacci, J. J., Salin, P., and Kerkerian-Le Goff, L. (2002). Systemic administration of dizocilpine maleate (MK-801) or L-dopa reverses the increases in GAD65 and GAD67 mRNA 
expression in the globus pallidus in a rat hemiparkinsonian model. Synapse 46, 224-234.

Ballion, B., Mallet, N., Bezard, E., Lanciego, J. L., and Gonon, F. (2008). Intratelencephalic corticostriatal neurons equally excite striatonigral and striatopallidal neurons and their discharge activity is selectively reduced in experimental parkinsonism. Eur. J. Neurosci. 27, 2313-2321.

Barroso-Chinea, P., Rico, A. J., PerezManso, M., Roda, E., Lopez, I. P., Luis-Ravelo, D., and Lanciego, J. L. (2008). Glutamatergic pallidothalamic projections and their implications in the pathophysiology of Parkinson's disease. Neurobiol. Dis. 31, 422-432.

Beckstead, R. M., Domesick, V. B., and Nauta, W. J. (1979). Efferent connections of the substantia nigra and ventral tegmental area in the rat. Brain Res. 175, 191-217.

Bergman, H., Wichmann, T., Karmon, B., and DeLong, M. R. (1994). The primate subthalamic nucleus. II. Neuronal activity in the MPTP model of parkinsonism. J. Neurophysiol. 72, 507-520.

Bevan,M.D.,Atherton, J.F., and Baufreton, J. (2006). Cellular principles underlying normal and pathological activity in the subthalamic nucleus. Curr. Opin. Neurobiol. 16, 621-628.

Bezard, E., Boraud, T., Bioulac, B., and Gross, C. E. (1999). Involvement of the subthalamic nucleus in glutamatergic compensatory mechanisms. Eur. J. Neurosci. 11, 2167-2170.

Bezard, E., Brotchie, J. M., and Gross, C. E. (2001a). Pathophysiology of levodopa-induced dyskinesia: potential for new therapies. Nat. Rev. Neurosci. 2, 577-588.

Bezard, E., Dovero, S., Prunier, C., Ravenscroft, P., Chalon, S., Guilloteau, D., Crossman, A. R., Bioulac, B., Brotchie, J. M., and Gross, C. E. (2001b). Relationship between the appearance of symptoms and the level of nigrostriatal degeneration in a progressive 1-methyl-4-phenyl1,2,3,6-tetrahydropyridine-lesioned macaque model of Parkinson's disease. J. Neurosci. 21, 6853-6861.

Boraud, T., Bezard, E., Bioulac, B., and Gross, C. E. (2000). Ratio of inhibited to activated pallidal neurons decreases dramatically during passive limb movements in the MPTPtreated monkey. J. Neurophysiol. 83, 1760-1763.

Boraud, T., Bezard, E., Bioulac, B., and Gross, C. E. (2001). Dopamine agonist-induced dyskinesias are correlated to both firing pattern and frequency alterations of pallidal neurones in the MPTP-treated monkey. Brain 124, 546-557.
Braak, H., Del Tredici, K., Bratzke, H., Hamm-Clement, J., Sandmann-Keil, D., and Rub, U. (2002). Staging of the intracerebral inclusion body pathology associated with idiopathic Parkinson's disease (preclinical and clinical stages). J. Neurol. 249(Suppl. 3), :III/1-5.

Calon, F., Birdi, S., Rajput, A. H., Hornykiewicz, O., Bedard, P. J., and Di Paolo, T. (2002). Increase of preproenkephalin mRNA levels in the putamen of Parkinson disease patients with levodopa-induced dyskinesias. J. Neuropathol. Exp. Neurol. 61, 186-196.

Carbon, M., Ghilardi, M. F., Feigin, A., Fukuda, M., Silvestri, G., Mentis, M. J., Ghez, C., Moeller, J. R., and Eidelberg, D. (2003). Learning networks in health and Parkinson's disease: reproducibility and treatment effects. Hum. Brain Mapp. 19, 197-211.

Carpenter, M. B., Nakano, K., and Kim, R. (1976). Nigrothalamic projections in the monkey demonstrated by autoradiographic technics. J. Comp. Neurol. 165, 401-415.

Carta,A., Fenu, S., and Morelli, M. (2001). Alterations in GAD67, dynorphin and enkephalin mRNA in striatal output neurons following priming in the 6-OHDA model of Parkinson's disease. Neurol. Sci. 22, 59-60.

Carta, A. R., Fenu, S., Pala, P., Tronci, E., and Morelli, M. (2003). Selective modifications in GAD67 mRNA levels in striatonigral and striatopallidal pathways correlate to dopamine agonist priming in 6-hydroxydopaminelesioned rats. Eur. J. Neurosci. 18, 2563-2572.

Castle, M., Aymerich, M. S., SanchezEscobar, C., Gonzalo, N., Obeso, J. A., and Lanciego, J. L. (2005). Thalamic innervation of the direct and indirect basal ganglia pathways in the rat: Ipsiand contralateral projections. J. Comp. Neurol. 483, 143-153.

Cenci, M. A., (2002). Transcription factors involved in the pathogenesis of L-DOPA-induced dyskinesia in a rat model of Parkinson's disease. Amino Acids 23, 105-109.

Cenci, M. A., Lee, C. S., and Bjorklund, A. (1998). L-DOPA-induced dyskinesia in the rat is associated with striatal overexpression of prodynorphin- and glutamic acid decarboxylase mRNA. Eur. J. Neurosci. 10, 2694-2706.

Chaudhuri, K. R., Healy, D. G., and Schapira, A. H. (2006). Non-motor symptoms of Parkinson's disease: diagnosis and management. Lancet Neurol. 5, 235-245.

Cherubini, E., Herrling, P. L., Lanfumey, L., and Stanzione, P. (1988). Excitatory amino acids in synaptic excitation of rat striatal neurones in vitro. J. Physiol. 400, 677-690.
Consolo, S., Morelli, M., Rimoldi, M. Giorgi, S., and Di Chiara, G. (1999). Increased striatal expression of glutamate decarboxylase 67 after priming of 6-hydroxydopamine-lesioned rats. Neuroscience 89, 1183-1187.

Crossman, A. R., (1987). Primate models of dyskinesia: the experimental approach to the study of basal gangliarelated involuntary movement disorders. Neuroscience 21, 1-40.

Day, M., Wang, Z., Ding, J., An, X., Ingham, C.A., Shering, A. F., Wokosin, D., Ilijic, E., Sun, Z., Sampson, A. R., Mugnaini, E., Deutch, A. Y., Sesack, S. R., Arbuthnott, G. W., and Surmeier, D. J. (2006). Selective elimination of glutamatergic synapses on striatopallidal neurons in Parkinson disease models. Nat. Neurosci. 9, 251-259.

de la Fuente-Fernandez, R., Ruth, T. J. Sossi, V., Schulzer, M., Calne, D. B., and Stoessl, A. J. (2001). Expectation and dopamine release: mechanism of the placebo effect in Parkinson's disease. Science 293, 1164-1166.

Degos, B., Deniau, J. M., Le Cam, J., Mailly, P., and Maurice, N. (2008). Evidence for a direct subthalamo-cortical loop circuit in the rat. Eur. J. Neurosci. 27, 2599-2610.

DeLong, M.R., (1990). Primate models of movement disorders of basal ganglia origin. Trends Neurosci. 13, 281-285.

DeLong, M. R., and Wichmann, T. (2007). Circuits and circuit disorders of the basal ganglia. Arch. Neurol. 64, 20-24.

Denner, L. A., and Wu, J. Y. (1985). Two forms of rat brain glutamic acid decarboxylase differ in their dependence on free pyridoxal phosphate. $J$. Neurochem. 44, 957-965.

Duty, S., Henry, B., Crossman, A. R., and Brotchie, J. M. (1998). Topographical organization of opioid peptide precursor gene expression following repeated apomorphine treatment in the 6-hydroxydopamine-lesioned rat. Exp. Neurol. 150, 223-234.

Eckert, T., Barnes, A., Dhawan, V., Frucht S., Gordon, M. F., Feigin, A. S., and Eidelberg, D. (2005). FDG PET in the differential diagnosis of parkinsonian disorders. Neuroimage 26, 912-921.

Eidelberg, D. (2009). Metabolic brain networks in neurodegenerative disorders: a functional imaging approach. Trends Neurosci. 32, 548-557.

Eidelberg, D., and Edwards, C. (2000). Functional brain imaging of movement disorders. Neurol. Res. 22, 305-312.

Engber, T. M., Boldry, R. C., Kuo, S., and Chase, T. N. (1992). Dopaminergic modulation of striatal neuropeptides: differential effects of D1 and D2 receptor stimulation on somatostatin, neuropeptide Y, neurotensin, dynorphin and enkephalin. Brain Res. 581, 261-268.

Faull, R. L., and Mehler, W. R. (1978). The cells of origin of nigrotectal, nigrothalamic and nigrostriatal projections in the rat. Neuroscience 3, 989-1002.

Feger, J., Bevan, M., and Crossman, A. R. (1994). The projections from the parafascicular thalamic nucleus to the subthalamic nucleus and the striatum arise from separate neuronal populations: a comparison with the corticostriatal and corticosubthalamic efferents in a retrograde fluorescent double-labelling study. Neuroscience 60, 125-132.

Feigin, A., Fukuda, M., Dhawan, V. Przedborski, S., Jackson-Lewis, V., Mentis, M. J., Moeller, J. R., and Eidelberg, D. (2001). Metabolic correlates of levodopa response in Parkinson's disease. Neurology 57, 2083-2088.

Filion, M., Tremblay, L., and Bedard, P. J. (1991). Effects of dopamine agonists on the spontaneous activity of globus pallidus neurons in monkeys with MPTP-induced parkinsonism. Brain Res. 547, 152-161.

Francois, C., Percheron, G., Yelnik, J., and Heyner, S. (1984). A Golgi analysis of the primate globus pallidus. I. Inconstant processes of large neurons, other neuronal types, and afferent axons. J. Comp. Neurol. 227, 182-199.

Gerfen, C. R. (2000). Molecular effects of dopamine on striatal-projection pathways. Trends Neurosci. 23, S64-S70.

Gerfen, C. R., Engber, T. M., Mahan, L. C., Susel, Z., Chase, T. N., Monsma, F. J. Jr., and Sibley, D. R. (1990). D1 and D2 dopamine receptor-regulated gene expression of striatonigral and striatopallidal neurons. Science 250, 1429-1432.

Granata, A. R., and Kitai, S. T. (1989). Intracellular analysis of excitatory subthalamic inputs to the pedunculopontine neurons. Brain Res. 488, 57-72.

Grofova, I., and Zhou, M. (1998). Nigral innervation of cholinergic and glutamatergic cells in the rat mesopontine tegmentum: light and electron microscopic anterograde tracing and immunohistochemical studies. J. Comp. Neurol. 395, 359-379.

Guigoni, C., Li, Q., Aubert, I., Dovero, S., Bioulac, B. H., Bloch, B., Crossman, A. R., Gross, C. E., and Bezard, E. (2005). Involvement of sensorimotor, limbic, and associative basal ganglia domains in L-3,4-dihydroxyphenylalanineinduced dyskinesia. J. Neurosci. 25 2102-2107.

Haber, S. N., Fudge, J. L., and McFarland, N.R. (2000). Striatonigrostriatal pathways in primates form an ascending 
spiral from the shell to the dorsolateral striatum. J. Neurosci. 20, 2369-2382.

Haber, S. N., Lynd-Balta, E., and Mitchell, S. J. (1993). The organization of the descending ventral pallidal projections in the monkey. J. Comp. Neurol. 329, 111-128.

Hammond, C., Rouzaire-Dubois, B., Feger, J., Jackson, A., and Crossman, A. R. (1983). Anatomical and electrophysiological studies on the reciprocal projections between the subthalamic nucleus and nucleus tegmenti pedunculopontinus in the rat. Neuroscience 9, 41-52.

Hazrati, L. N., Parent, A., Mitchell, S., and Haber, S. N. (1990). Evidence for interconnections between the two segments of the globus pallidus in primates: a PHA-L anterograde tracing study. Brain Res. 533, 171-175.

Henry, B., Crossman, A. R., and Brotchie, J. M. (1999). Effect of repeated L-DOPA, bromocriptine, or lisuride administration on preproenkephalin-A and preproenkephalin-B mRNA levels in the striatum of the 6-hydroxydopaminelesioned rat. Exp. Neurol. 155, 204-220.

Henry, B., Duty, S., Fox, S. H., Crossman, A. R., and Brotchie, J. M. (2003). Increased striatal pre-proenkephalin $\mathrm{B}$ expression is associated with dyskinesia in Parkinson's disease. Exp. Neurol. 183, 458-468.

Herrero, M. T., Augood, S. J., Hirsch, E. C., Javoy-Agid, F., Luquin, M. R., Agid, Y., Obeso, J. A., and Emson, P. C. (1995). Effects of L-DOPA on preproenkephalin and preprotachykinin gene expression in the MPTP-treated monkey striatum. Neuroscience 68, 1189-1198.

Herrero, M. T., Levy, R., Ruberg, M., Luquin, M. R., Villares, J., Guillen, J., Faucheux, B., Javoy-Agid, F., Guridi, J., Agid, Y., Obeso, J. A., and Hirsch, E. C. (1996). Consequence of nigrostriatal denervation and L-dopa therapy on the expression of glutamic acid decarboxylase messenger RNA in the pallidum. Neurology 47, 219-224.

Hikosaka, O., Nakamura, K., Sakai, K., and Nakahara, H. (2002). Central mechanisms of motor skill learning. Curr. Opin. Neurobiol. 12, 217-222.

Hirano, S., Asanuma, K., Ma, Y., Tang, C., Feigin, A., Dhawan, V., Carbon, M., and Eidelberg, D. (2008). Dissociation of metabolic and neurovascular responses to levodopa in the treatment of Parkinson's disease. J. Neurosci. 28, 4201-4209.

Huang, C., Tang, C., Feigin, A., Lesser, M., Ma, Y., Pourfar, M., Dhawan, V., and Eidelberg, D. (2007). Changes in network activity with the progression of Parkinson's disease. Brain 130, 1834-1846.
Ingham, C.A., Hood, S. H., Taggart, P., and Arbuthnott, G.W. (1998). Plasticity of synapses in the rat neostriatum after unilateral lesion of the nigrostriatal dopaminergic pathway. J. Neurosci. $18,4732-4743$.

Jackson, A., and Crossman, A. R. (1981). Subthalamic nucleus efferent projection to the cerebral cortex. Neuroscience 6, 2367-2377.

Jackson, A., and Crossman, A. R. (1983). Nucleustegmentipedunculopontinus: efferent connections with special reference to the basal ganglia, studied in the rat by anterograde and retrograde transport of horseradish peroxidase. Neuroscience 10, 725-765.

Jenner, P., (2008). Molecular mechanisms of L-DOPA-induced dyskinesia. Nat. Rev. Neurosci. 9, 665-677.

Kaufman, D. L., Houser, C. R., and Tobin, A. J. (1991). Two forms of the gammaaminobutyric acid synthetic enzyme glutamate decarboxylase have distinct intraneuronal distributions and cofactor interactions. J. Neurochem. $56,720-723$.

Kawaguchi, Y., Wilson, C. J., and Emson, P. C. (1990). Projection subtypes of rat neostriatal matrix cells revealed by intracellular injection of biocytin. J. Neurosci. 10, 3421-3438.

Kelly, R. M., and Strick, P. L. (2004). Macro-architecture of basal ganglia loops with the cerebral cortex: use of rabies virus to reveal multisynaptic circuits. Prog. Brain Res. 143, 449-459.

Kemp, J. M., and Powell, T. P. (1970). The cortico-striate projection in the monkey. Brain 93, 525-546.

Kemp, J. M., and Powell, T. P. (1971). The structure of the caudate nucleus of the cat: light and electron microscopy. Philos. Trans. R. Soc. Lond., B, Biol. Sci 262, 383-401.

Kha, H. T., Finkelstein, D. I., Pow, D. V., Lawrence, A. J., and Horne, M. K. (2000). Study of projections from the entopeduncular nucleus to the thalamus of the rat. J. Comp. Neurol. 426, 366-377.

Kincaid, A. E., Albin, R. L., Newman, S. W., Penney, J. B., and Young, A. B. (1992). 6-Hydroxydopamine lesions of the nigrostriatal pathway alter the expression of glutamate decarboxylase messenger RNA in rat globus pallidus projection neurons. Neuroscience 51, 705-718.

Kincaid, A. E., Penney, J. B. Jr., Young, A. B., and Newman, S. W. (1991). Evidence for a projection from the globus pallidus to the entopeduncular nucleus in the rat. Neurosci. Lett. 128, 121-125.

Kita, H., and Kitai, S. T. (1987). Efferent projections of the subthalamic nucleus in the rat: light and electron microscopic analysis with the
PHA-L method. J. Comp. Neurol. 260, 435-452.

Kita, H., and Kitai, S. T. (1988). Glutamate decarboxylase immunoreactive neurons in rat neostriatum: their morphological types and populations. Brain Res. 447, 346-352.

Kitai, S. T., Kocsis, J. D., Preston, R. J., and Sugimori, M. (1976). Monosynaptic inputs to caudate neurons identified by intracellular injection of horseradish peroxidase. Brain Res. 109 601-606.

Kravitz, A. V., Freeze, B. S., Parker, P. R., Kay, K., Thwin, M. T., Deisseroth, K., and Kreitzer, A. C. (2010). Regulation of parkinsonian motor behaviours by optogenetic control of basal ganglia circuitry. Nature 466, 622-626.

Lanciego, J. L., Gonzalo, N., Castle, M., Sanchez-Escobar, C., Aymerich, M. S., and Obeso, J. A. (2004). Thalamic innervation of striatal and subthalamic neurons projecting to the rat entopeduncular nucleus. Eur. J. Neurosci. 19 , 1267-1277.

Le Moine, C., and Bloch, B. (1995).D1 and D2 dopamine receptor gene expression in the rat striatum: sensitive cRNA probes demonstrate prominent segregation of D1 and D2 mRNAs in distinct neuronal populations of the dorsal and ventral striatum. J. Comp. Neurol. 355, 418-426.

Lei, W., Jiao, Y., Del Mar, N., and Reiner, A. (2004). Evidence for differential cortical input to direct pathway versus indirect pathway striatal projection neurons in rats. J. Neurosci. 24 8289-8299.

Levesque, M., and Parent, A. (2005). The striatofugal fiber system in primates: a reevaluation of its organization based on single-axon tracing studies. Proc. Natl. Acad. Sci. U.S.A. 102 11888-11893.

Levy, R., Herrero, M-T., Ruberg, M., Villares, J., Faucheux, B., Guridi, J., Guillen, J., Luquin, M. R., Javoy-Agid F., Obeso, J. A., Agid, Y., and Hirsch, E. C. (1995). Effects of nigrostriatal denervation and L-dopa therapy on the GABAergic neurons in the striatum in MPTP-treated monkeys and Parkinson's disease: an in situ hybridization study of GAD67 mRNA. Eur. J. Neurosci. 7, 1199-1209.

Lindefors, N., Brene, S., HerreraMarschitz, M., and Persson, H. (1989). Region specific regulation of glutamic acid decarboxylase mRNA expression by dopamine neurons in rat brain. Exp. Brain Res. 77, 611-620.

Mallet, N., Ballion, B., Le Moine, C., and Gonon, F. (2006). Cortical inputs and GABA interneurons imbalance projection neurons in the striatum of parkinsonian rats. J. Neurosci. 26 3875-3884.
Martin, D. L., Martin, S. B., Wu, S. J., and Espina, N. (1991). Regulatory properties of brain glutamate decarboxylase (GAD): the apoenzyme of GAD is present principally as the smaller of two molecular forms of GAD in brain. J. Neurosci. 11, 2725-2731.

Martin, D. L., and Rimvall, K. (1993). Regulation of gamma-aminobutyric acid synthesis in the brain. $J$. Neurochem. 60, 395-407.

McGeer, P. L., McGeer, E. G., Scherer, U., and Singh, K. (1977). A glutamatergic corticostriatal path? Brain Res 128, 369-373.

Merchenthaler, I., Maderdrut, J. L., Cianchetta, P., Shughrue, P., and Bronstein, D. (1997). In situ hybridization histochemical localization of prodynorphin messenger RNA in the central nervous system of the rat. J. Comp. Neurol. 384, 211-232.

Merello, M., Balej, J., Delfino, M., Cammarota, A., Betti, O., and Leiguarda, R. (1999). Apomorphine induces changes in GPi spontaneous outflow in patients with Parkinson's disease. Mov. Disord. 14, 45-49.

Mink, J. W. (1996). The basal ganglia: focused selection and inhibition of competing motor programs. Prog. Neurobiol. 50, 381-425.

Mitchell, I. J., Boyce, S., Sambrook, M. A., and Crossman, A. R. (1992). A 2-deoxyglucose study of the effects of dopamine agonists on the parkinsonian primate brain. Implications for the neural mechanisms that mediate dopamine agonist-induced dyskinesia. Brain 115 (Pt 3), 809-824.

Mitchell, I. J., Clarke, C. E., Boyce, S., Robertson, R. G., Peggs, D., Sambrook, M. A., and Crossman, A. R. (1989). Neural mechanisms underlying parkinsonian symptoms based upon regional uptake of 2-deoxyglucose in monkeys exposed to 1-methyl-4-phenyl-1,2,3,6tetrahydropyridine. Neuroscience 32, 213-226.

Monakow, K. H., Akert, K., and Kunzle, H. (1979). Projections of precentral and premotor cortex to the red nucleus and other midbrain areas in Macaca fascicularis. Exp. Brain Res. 34, 91-105.

Morissette, M., Goulet, M., Soghomonian, J. J., Blanchet, P. J., Calon, F., Bedard, P. J., and Di Paolo, T. (1997). Preproenkephalin mRNA expression in the caudate-putamen of MPTP monkeys after chronic treatment with the D2 agonist U91356A in continuous or intermittent mode of administration: comparison with L-DOPA therapy. Brain Res. Mol. Brain Res. 49, 55-62.

Morissette, M., Grondin, R., Goulet, M., Bedard, P. J., and Di Paolo, T. (1999). Differential regulation of striatal preproenkephalin and preprotachykinin 
mRNA levels in MPTP-lesioned monkeys chronically treated with dopamine $\mathrm{D} 1$ or $\mathrm{D} 2$ receptor agonists. J. Neurochem. 72, 682-692.

Murakami, S., Inagaki, S., Shimada, S., Kubota, Y., Kito, S., Ogawa, N., and Takagi, H. (1989a). The colocalization of substance P- and somatostatin-like peptides in neurons of the entopeduncular nucleus of rats. Peptides 10, 973-977.

Murakami, S., Kubota, Y., Kito, S., Shimada, S., Takagi, H., Wu, J. Y., and Inagaki, S. (1989b). The coexistence of substance P- and glutamic acid decarboxylase-like immunoreactivity in entopeduncular neurons of the rat. Brain Res. 485, 403-406.

Nadjar, A., Brotchie, J. M., Guigoni, C., Li, Q., Zhou, S. B., Wang, G. J., Ravenscroft, P., Georges, F., Crossman, A. R., and Bezard,E. (2006). Phenotype of striatofugal medium spiny neurons in parkinsonian and dyskinetic nonhuman primates: a call for a reappraisal of the functional organization of the basal ganglia. J. Neurosci. 26, 8653-8661.

Nambu, A., Tokuno, H., Inase, M., and Takada,M.(1997).Corticosubthalamic input zones from forelimb representations of the dorsal and ventral divisions of the premotor cortex in the macaque monkey: comparison with the input zones from the primary motor cortex and the supplementary motor area. Neurosci. Lett. 239, 13-16.

Nambu, A., Tokuno, H., and Takada, M. (2002). Functional significance of the cortico-subthalamo-pallidal 'hyperdirect' pathway. Neurosci. Res. $43,111-117$.

Nauta, H. J., and Cole, M. (1978). Efferent projections of the subthalamic nucleus: an autoradiographic study in monkey and cat. J. Comp. Neurol. 180, 1-16.

Nielsen, K. M., and Soghomonian, J. J. (2004). Normalization of glutamate decarboxylase gene expression in the entopeduncular nucleus of rats with a unilateral 6-hydroxydopamine lesion correlates with increased GABAergic input following intermittent but not continuous levodopa. Neuroscience 123, 31-42.

Nisbet,A.P., Foster, O.J., Kingsbury,A.,Eve, D. J., Daniel, S. E., Marsden, C. D., and Lees, A. J. (1995). Preproenkephalin and preprotachykinin messenger RNA expression in normal human basal ganglia and in Parkinson's disease. Neuroscience 66, 361-376.

Obeso, J. A., Rodriguez, M. C., and DeLong, M. R. (1997). Basal ganglia pathophysiology. A critical review. Adv. Neurol. 74, 3-18.

Obeso, J. A., Rodriguez-Oroz, M. C., Rodriguez, M., DeLong, M. R., and Olanow,C.W.(2000).Pathophysiology of levodopa-induced dyskinesias in Parkinson's disease: problems with the current model. Ann. Neurol. 47, S22-S32; discussion S32-S34.

Oertel, W. H., and Mugnaini, E. (1984). Immunocytochemical studies of GABAergic neurons in rat basal ganglia and their relations to other neuronal systems. Neurosci. Lett. 47, 233-238.

Parent, A., Boucher, R., and O'Reilly-Fromentin, J. (1981). Acetylcholinesterase-containing neurons in cat pallidal complex; morphological characteristics and projection towards the neocortex. Brain Res. 230, 356-361.

Parent, A., and De Bellefeuille, L. (1982). Organization of efferent projections from the internal segment of globus pallidus in primate as revealed by fluorescence retrograde labeling method. Brain Res. 245, 201-213.

Parent, A., and Hazrati, L. N. (1995). Functional anatomy of the basal ganglia. I. The cortico-basal gangliathalamo-cortical loop. Brain Res. Brain Res. Rev. 20, 91-127.

Parent, A., Sato, F., Wu, Y., Gauthier, J., Levesque, M., and Parent, M. (2000). Organization of the basal ganglia: the importance of axonal collateralization. Trends Neurosci. 23, S20-S27.

Parent, A., and Smith, Y. (1987). Organization of efferent projections of the subthalamic nucleus in the squirrel monkey as revealed by retrograde labeling methods. Brain Res. 436, 296-310.

Pasupathy, A., and Miller, E. K. (2005). Different time courses of learningrelated activity in the prefrontal cortex and striatum. Nature 433, 873-876.

Pedneault, S., and Soghomonian, J. J. (1994). Glutamate decarboxylase (GAD65) mRNA levels in the striatum and pallidum of MPTP-treated monkeys. Brain Res. Mol. Brain Res. 25, 351-354.

Penney, J. B. Jr., and Young, A. B. (1981). GABA as the pallidothalamic neurotransmitter: implications for basal ganglia function. Brain Res. 207, 195-199.

Porter, R. H., Greene, J. G., Higgins, D. S. Jr., and Greenamyre, J. T. (1994). Polysynaptic regulation of glutamate receptors and mitochondrial enzyme activities in the basal ganglia of rats with unilateral dopamine depletion. J. Neurosci. 14, 7192-7199.

Rajakumar, N., Elisevich, K., and Flumerfelt, B.A. (1994). Parvalbumincontaining GABAergic neurons in the basal ganglia output system of the rat. J. Comp. Neurol. 350, 324-336.

Rascol, O., Brooks, D. J., Korczyn, A. D., De Deyn, P. P., Clarke, C. E., and Lang, A. E. (2000). A five-year study of the incidence of dyskinesia in patients with early Parkinson's disease who were treated with ropinirole or levodopa. N. Engl. J. Med. 342, 1484-1491.

Rico, A. J., Barroso-Chinea, P., ContePerales, L., Roda, E., Gomez-Bautista, V., Gendive, M., Obeso, J. A., and Lanciego, J. L. (2010). A direct projection from the subthalamic nucleus to the ventral thalamus in monkeys. Neurobiol. Dis. 39, 381-392.

Rodriguez-Oroz, M. C., Jahanshahi, M. Krack, P., Litvan, I., Macias, R., Bezard, E., and Obeso, J. A. (2009). Initial clinical manifestations of Parkinson's disease: features and pathophysiological mechanisms. Lancet Neurol. 8, 1128-1139.

Sadikot, A. F., Parent, A., and Francois, C (1992). Efferent connections of the centromedian and parafascicular thalamic nuclei in the squirrel monkey: a PHA-L study of subcortical projections. J. Comp. Neurol. 315, 137-159.

Saka, E., Elibol, B., Erdem, S., and Dalkara, T. (1999). Compartmental changes in expression of c-Fos and FosB proteins in intact and dopamine-depleted striatum after chronic apomorphine treatment. Brain Res. 825, 104-114.

Scholz, B., Svensson, M., Alm, H., Skold, K., Falth, M., Kultima, K., Guigoni, C. Doudnikoff, E., Li, Q., Crossman, A. R., Bezard, E., and Andren, P.E. (2008). Striatal proteomic analysis suggests that first L-dopa dose equates to chronic exposure. PLoS ONE 3:e1589. doi: 10.1371/journal.pone.0001589.

Schroeder,J.A., and Schneider, J.S. (2001) Alterations in expression of messenger RNAs encoding two isoforms of glutamic acid decarboxylase in the globus pallidus and entopeduncular nucleus in animals symptomatic for and recovered from experimental Parkinsonism. Brain Res. 888 , 180-183.

Sidibe, M., Bevan, M. D., Bolam, J. P., and Smith,Y. (1997). Efferent connections of the internal globus pallidus in the squirrel monkey: I. Topography and synaptic organization of the pallidothalamic projection. J. Comp. Neurol. 382, 323-347.

Sidibe, M., Pare, J. F., and Smith, Y. (2002). Nigral and pallidal inputs to functionally segregated thalamostriatal neurons in the centromedian/ parafascicular intralaminar nuclear complex in monkey. J. Comp. Neurol. 447, 286-299.

Smith, Y., Hazrati, L. N., and Parent, A. (1990). Efferent projections of the subthalamic nucleus in the squirrel monkey as studied by the PHA-L anterograde tracing method. J. Comp. Neurol. 294, 306-323.

Soghomonian, J. J., and Chesselet, M. F. (1992). Effects of nigrostriatal lesions on the levels of messenger RNAs encoding two isoforms of glutamate decarboxylase in the globus pallidus and entopeduncular nucleus of the rat. Synapse 11, 124-133.

Soghomonian, J. J., Gonzales, C., and Chesselet, M. F. (1992). Messenger RNAs encoding glutamatedecarboxylases are differentially affected by nigrostriatal lesions in subpopulations of striatal neurons. Brain Res. 576, 68-79.

Soghomonian, J. J., Pedneault, S., Audet, G., and Parent, A. (1994). Increased glutamate decarboxylase mRNA levels in the striatum and pallidum of MPTP-treated primates. J. Neurosci. 14, 6256-6265.

Steininger, T. L., Rye, D. B., and Wainer, B. H. (1992). Afferent projections to the cholinergic pedunculopontine tegmental nucleus and adjacent midbrain extrapyramidal area in the albino rat. I. Retrograde tracing studies. J. Comp Neurol. 321, 515-543.

Stephens, B., Mueller, A. J., Shering, A. F., Hood, S. H., Taggart, P., Arbuthnott, G.W., Bell, J.E., Kilford, L., Kingsbury, A. E., Daniel, S. E., and Ingham, C. A. (2005). Evidence of a breakdown of corticostriatal connections in Parkinson's disease. Neuroscience 132, 741-754.

Stephenson, D. T., Li, Q., Simmons, C., Connell, M. A., Meglasson, M. D., Merchant, K., and Emborg, M. E. (2005). Expression of GAD65 and GAD67 immunoreactivity in MPTPtreated monkeys with or without L-DOPA administration. Neurobiol. Dis. 20, 347-359.

Suarez, J. I., Metman, L. V., Reich, S. G., Dougherty, P. M., Hallett, M., and Lenz, F. A. (1997). Pallidotomy for hemiballismus: efficacy and characteristics of neuronal activity. Ann. Neurol. $42,807-811$.

Tel, B. C., Zeng, B. Y., Cannizzaro, C., Pearce, R. K., Rose, S., and Jenner, P. (2002). Alterations in striatal neuropeptide mRNA produced by repeated administration of L-DOPA, ropinirole or bromocriptine correlate with dyskinesia induction in MPTP-treated common marmosets. Neuroscience 115, 1047-1058.

Trost, M., Su, S., Su, P., Yen, R. F., Tseng, H. M., Barnes, A., Ma, Y., and Eidelberg, D. (2006). Network modulation by the subthalamic nucleus in the treatment of Parkinson's disease. Neuroimage 31 , 301-307.

Van Der Kooy, D., and Hattori, T. (1980). Single subthalamic nucleus neurons project to both the globus pallidus and substantia nigra in rat. J. Comp. Neurol. 192, 751-768.

Vidailhet, M., Bonnet, A. M., Marconi, R., Durif, F., and Agid, Y. (1999). The 
phenomenology of L-dopa-induced dyskinesias in Parkinson's disease. Mov. Disord. 14 (Suppl. 1), 13-18.

Vila, M.,Levy, R., Herrero, M. T., Faucheux, B., Obeso, J. A., Agid, Y., and Hirsch, E. C. (1996). Metabolic activity of the basal ganglia in parkinsonian syndromes in human and non-human primates: a cytochrome oxidase histochemistry study. Neuroscience 71, 903-912.

Vila, M., Marin, C., Ruberg, M., Jimenez, A., Raisman-Vozari, R., Agid, Y., Tolosa, E., and Hirsch, E. C. (1999). Systemic administration of NMDA and AMPA receptor antagonists reverses the neurochemical changes induced by nigrostriatal denervation in basal ganglia. J. Neurochem. 73 , 344-352.

Villalba, R. M., Lee, H., and Smith, Y. (2009). Dopaminergic denervation and spine loss in the striatum of MPTP-treated monkeys. Exp. Neurol. 215, 220-227.

Vitek, J. L., Chockkan, V., Zhang, J. Y., Kaneoke, Y., Evatt, M., DeLong, M. R.,
Triche, S., Mewes, K., Hashimoto, T., and Bakay, R. A. (1999). Neuronal activity in the basal ganglia in patients with generalized dystonia and hemiballismus. Ann. Neurol. 46, 22-35.

Westin, J. E., Andersson, M., Lundblad, M., and Cenci, M. A. (2001). Persistent changes in striatal gene expression induced by long-term L-DOPA treatment in a rat model of Parkinson's disease. Eur. J. Neurosci. 14, 1171-1176.

Wichmann, T., and DeLong, M. R. (1996). Functional and pathophysiological models of the basal ganglia. Curr. Opin. Neurobiol. 6, 751-758.

Wilson, C. J., Chang, H. T., and Kitai, S. T. (1983). Origins of post synaptic potentials evoked in spiny neostriatal projection neurons by thalamic stimulation in the rat. Exp. Brain Res. 51, 217-226.

Winkler, C., Kirik, D., Bjorklund, A., and Cenci, M.A. (2002).L-DOPA-induced dyskinesia in the intrastriatal 6-hydroxydopamine model of parkinson's disease: relation to motor and cellular parameters of nigrostriatal function. Neurobiol. Dis. 10, 165-186.

Wong-Riley, M. T., (1989). Cytochrome oxidase: an endogenous metabolic marker for neuronal activity. Trends Neurosci. 12, 94-101.

Wong-Riley, M. T., and Welt, C. (1980). Histochemical changes in cytochrome oxidase of cortical barrels after vibrissal removal in neonatal and adult mice. Proc. Natl. Acad. Sci. U.S.A. 77 , 2333-2337.

Yahr, M. D., Duvoisin, R. C., Hoehn, M. M., Schear, M. J., and Barrett, R. E. (1968). L-Dopa (L-3,4dihydroxyphenylanine) - its clinical effects in parkinsonism. Trans. Am. Neurol. Assoc. 93, 56-63.

Yin, H.H., and Knowlton, B. J. (2006). The role of the basal ganglia in habit formation. Nat. Rev. Neurosci. 7, 464-476.

Zeng, B. Y., Pearce, R. K., MacKenzie, G. M., and Jenner, P. (2000). Alterations in preproenkephalin and adenosine-2a receptor mRNA, but not preprotachykinin mRNA correlate with occurrence of dyskinesia in normal monkeys chronically treated with L-DOPA. Eur. J. Neurosci. 12, 1096-1104.

Conflict of Interest Statement: The authors declare that the research was conducted in the absence of any commercial or financial relationships that could be construed as a potential conflict of interest.

Received:29July 2010; paperpending published: 13 August 2010; accepted: 24 August 2010; published online: 14 September 2010.

Citation: Barroso-Chinea P and Bezard E (2010) Basal ganglia circuits underlying the pathophysiology of levodopa-induced dyskinesia. Front. Neuroanat. 4:131 doi: 10.3389/fnana.2010.00131

Copyright $\odot 2010$ Barroso-Chinea and Bezard. This is an open-access article subject to an exclusive license agreement between the authors and the Frontiers Research Foundation, which permits unrestricted use, distribution, and reproduction in any medium, provided the original authors and source are credited. 